\section{Children and adults affected by Cri du Chat syndrome: Care's recommendations}

\author{
Maria Elena Liverani, ${ }^{1}$ Alice Spano, ${ }^{2}$ \\ Cesare Danesino, ${ }^{2}$ Michela Malacarne, ${ }^{3}$ \\ Simona Cavani, ${ }^{3}$ Marianna Spunton, ${ }^{4}$ \\ Andrea Guala ${ }^{4}$ \\ 1 UOC Pediatria, Ospedale S. Andrea, \\ Roma; ${ }^{2}$ Dipartimento di Medicina \\ Molecolare, Università di Pavia; \\ ${ }^{3}$ UOC Laboratorio di Genetica Umana, \\ IRCCS G.Gaslini, Genova; \\ ${ }^{4}$ SOC Pediatria, Ospedale Castelli, \\ Verbania, Italy
}

\begin{abstract}
Our objective is to collect data and information for a better care and follow up in Cri du Chat patients. We conducted a literature review in August 2017 and then discuss the outcomes within the $\mathrm{ABC}$ (Associazione Bambini Cri du Chat, Italian $\mathrm{CdC}$ families support group). A proposal for clinical, laboratory and imaging work up should be performed at various ages in $\mathrm{CdC}$ patients. Follow up and rehabilitation should continue lifelong as some improvements can be obtained also in older ages and not to lose acquired skills.
\end{abstract}

\section{Introduction}

Cri du Chat syndrome (CdC) (OMIM 123450, ORPHA281) is a rare disorder due to a deletion of part of the short arm of chromosome 5 . The size of the deletion may vary from 5 to 40 MB.1,2 Deletion occurs as a de novo event in $85 \%$ of patients. In the majority of cases it is of paternal origin while in the remaining cases one of the parents is a carrier of a balanced structural chromosomal rearrangement. $3 \mathrm{CdC}$ incidence is estimated between $1 / 15000$ and $1 / 50.000$ live borns; ${ }^{2}$ literature data report $10 \%$ of mortality, $75 \%$ of which occurs within the first year. Survival has improved over the years, and the oldest Italian patient known is now in his seventies. 4

Cornish and Bramble (2002) $)^{5}$ discussed generally the recommendations for clinical management, but little is known about the clinical assessments that are required during infancy, adolescence and adulthood to detect the most frequent complications at an early stage. In 1994 a Clinical-Genetic study Group within the Italian Society for Pediatrics published recommendations on how to manage and follow up in Cri du Chat patients. Authors wrote the proposal according to their experience on 90 cases of various ages included in the Italian $\mathrm{CdC}$ database. ${ }^{6}$ Operators' personal experience combined with new data from the literature allowed to further improve medical and social prognosis for $\mathrm{CdC}$ patients, including their own and family's quality of life. Instrumental contributions derived from the collaboration between researchers and families, supported by ABC (Associazione Bambini Cri du Chat, www.criduchat.it).

Ever since 1998, yearly meetings have been bringing together families and children from all over Italy. Scientific seminars and care training courses are held as a part of these yearly meetings. Additionally, parents have the opportunity to discuss with many consultants to plan a follow up tailored to their own child. $\mathrm{ABC}$, through the recruitment of Italian families, made possible the development of a database including now more than 305 Italian patients. The database is intended to gather new clinical information and to allow a better description of the natural history of the disease. After 20 years, the $\mathrm{ABC}$ scientific committee considers it appropriate to propose new recommendations for general care and follow up of $\mathrm{CdC}$ patients.

\section{Diagnosis}

A diagnosis of deletion of the short arm of chromosome 5 can be obtained serendipitously prenatally after chorionic villus sampling of amniocentesis; usually this is performed in consideration of maternal age or due to abnormal ultrasound findings. In addition to conventional cytogenetics and Comparative Genomic Hybridisation (CGH array), fetal DNA analysis on maternal blood is a most recent method able to identify the deletion. After a diagnosis is obtained, saving biological material in a biobank seems wise.

In newborns, the association of the peculiar cat-like cry together with low birth weight, microcephaly and facial dysmorphisms will suggest the diagnosis.

$\mathrm{CGH}$ array is nowadays the main diagnostic test as it is able to define the breakpoint(s) and deletion size, and to identify other structural rearrangements in different chromosomes when concurrently present. Additional genomic variations are present in about $10 \%$ of cases (MM, personal communication). Conventional cytogenetic or FISH analysis will identify parental chromosomal structural abnormalities in a minority of families (about $10 \%$ of cases).
Correspondence: Maria Elena Liverani, UOC Pediatria, Azienda Ospedaliero-Universitaria Sant'Andrea Roma, Via di Grottarossa 10351039, 00189 Roma, Italy.

Tel.: +39-3477899845

E-mail: mariaelena.liverani@uniroma1.it

Key words: Cri du Chat; recommendations; best practices.

Contributions: the authors contributed equally.

Conflict of interest: the authors declare no potential conflict of interest.

Funding: $\mathrm{MS}$ is supported by a grant from $\mathrm{ABC}$ (Associazione Italiana Bambini Cri du Chat).

Received for publication: 20 August 2018.

Revision received: 31 January 2019.

Accepted for publication: 19 February 2019.

This work is licensed under a Creative Commons Attribution NonCommercial 4.0 License (CC BY-NC 4.0)

CCopyright M.E. Liverani et al., 2019

Licensee PAGEPress, Italy

Pediatric Reports 2019; 11:7839

doi:10.4081/pr.2019.7839

Pre-test genetic counselling is mandatory (as for any genetic test) to explain which are the planned tests, the expected results and their limitations. In the post-test counselling, it is important to inform the family about their child's condition, provide information about the syndrome, and help the parents to cope with the diagnosis. Of course, if a translocation is present, counselling will include discussion as to reproductive options and extension of genetic tests to other family members.

\section{Neonatal period}

Delivery by caesarean section occurs in $38 \%$ of cases, very close to the rate of the Italian population, $36.3 \% .{ }^{7}$ Extra uterine life adaptation is difficult and respiratory assistance is often needed. About $47 \%$ of Italian patients have been in a neonatal Intensive Care Unit due to low birth weight, respiratory distress, and muscular hypotonia. ${ }^{3}$ Low birth weight and inefficient sucking result in difficulties to start breastfeeding. Instructions to mother for milk production, feeding by gavage or spoon will help in solving the problem.

A complete cardiologic evaluation with ECG and ultrasound is suggested in order to rule out any cardiac malformation. Although 
the exact incidence of cardiac anomalies among patients with CDC is still undetermined, some studies estimated them to affect $15 \%$ to $20 \%$ of patients. In patients with an unbalanced translocation, this percentage rises up to $55 \%$ and it is associated with more complex diagnoses, such as Fallot tetralogy and endocardial cushion defect. ${ }^{8}$ As initial assessment, in the first few days, pulse oxymetry can be useful to monitor the patient. ${ }^{9}$ Otoacoustic emissions and ocular red reflex will be performed as in every newborn. ${ }^{10,11}$ In addition, metabolic screening for 38 metabolic disorders which is now offered to the Italian families will also be performed. ${ }^{12}$ We strongly suggest to include transfontanellar ultrasound as it is an easy, widely available, non-invasive test which will disclose a large number of brain malformations. MRI reports demonstrated abnormalities in the brain stem and cerebellar hypoplasia in a few cases; 13,14 however at present data from brain imaging do not seem to help in patient management, therefore, if and when to perform MR it is still under discussion. Neurological examination and psychiatric evaluation should be planned in the first few weeks (or as soon as possible after the diagnosis), to start a custom rehabilitation program.

\section{First year}

The first year of life is the most relevant to set up future development.15 Regular clinical evaluations are important; the recurrence of controls currently applied in Italy (at 15 days, 2/3 months, 5/6 months, 12 months) seems appropriate also for $\mathrm{CdC}$ patients. CdC patients will follow the same vaccinations scheduled as for unaffected children according to each national immunization program.

$\mathrm{ABC}$ published some recommendations in both English and Italian to help parents (together with pediatricians, physical therapists, teachers and various professionals involved in the children's education) to understand problems related to developmental delay and steps useful to achieve the best possible results. ${ }^{16}$ It is widely recognized that family involvement in educational and rehabilitation programs allows to achieve the best psychomotor, linguistic and relational development of the child (Figure 1). 16,17

While setting up clinical examination, it is important to plan an anesthesiology evaluation in preparation of surgery or in preparation of diagnostic tests which would require immobilization and sedation. This is needed by $40 \%$ of the patients during their life. ${ }^{18}$ Most of these surgeries are elective procedures performed in the first few years of life, so we would recommend the anesthesiology evaluation to take place in a hospital close to the patient's home, where surgery or diagnostic tests will be performed. An "anesthetic card" is also suggested in order to bring medical information with the patient at every examination. Anesthetic complications often described in the past appear nowadays less relevant. 18

\section{Infancy}

Although a specific immunological deficiency is not a distinctive feature of $\mathrm{CdC}$ patients, to prevent infectious diseases, typical of crowded infantile communities, parents should avoid early placing of children in nursery school.

Family pediatrician will take care of follow-up medical care, as for any child. In our experience, quite often families delegate everyday clinical practice to medical geneticists or other consultants.

Because of the importance of creating a calm and familiar pediatrician-child relationship we tend to disagree with the above approach. The pediatrician-child relationship is important to manage common
MONTHS

\section{GROSS MOTOR}

Sit no support (21)

Walk alone (19)

FINE MOTOR

Grasps (25)

Scribble (20)

\section{LANGUAGE}

First word (21)

Point two pictures (21)

PERSONAL-SOCIAL

Drink from cup (19)

Wash and dry hands $(20)$

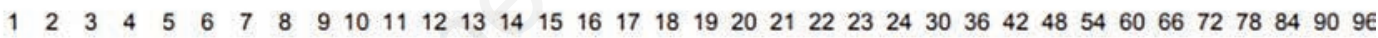

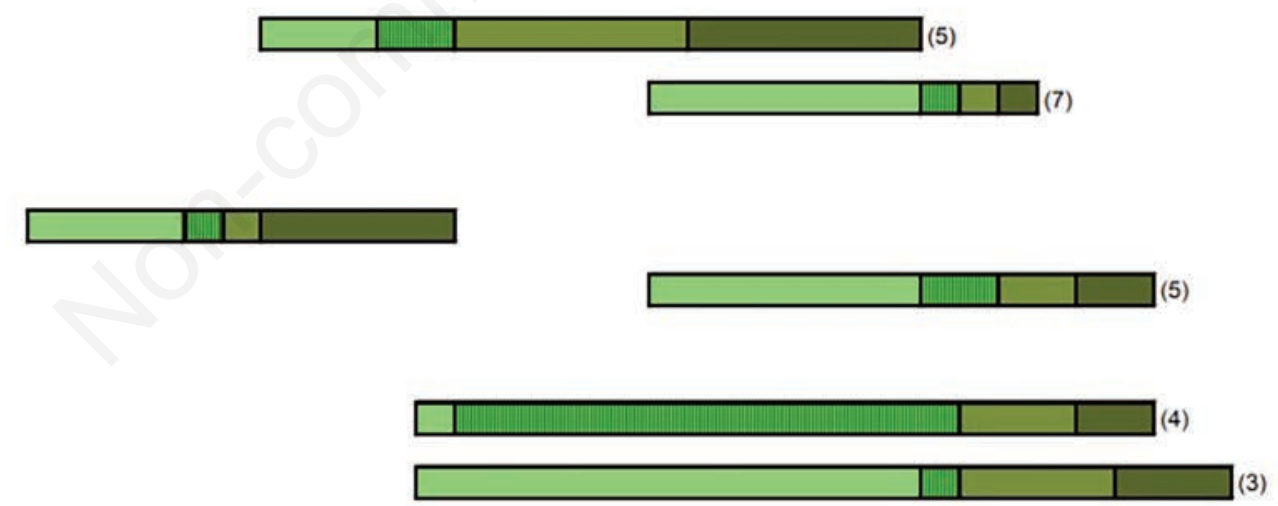

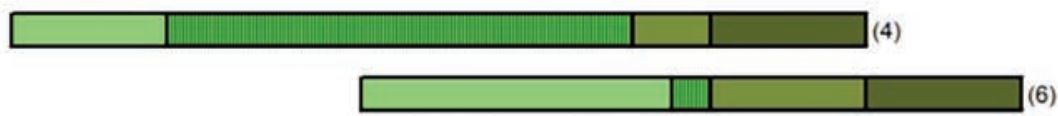

Figure 1. Age of achievement in Italian Cri du chat patients (in the left brackets the number of patients studied, in the right brackets the number of patients which have not yet achieved the development step). 
illnesses (for which there is no requirement for hospital assessment), and growth evaluation in a quiet and friendly setting. Syndrome-specific growth charts are available to monitor child's weight, length/stature, and head circumference. 19

The common presence of malocclusion in $\mathrm{CdC}$ syndrome requires an early orthodontic assessment. Indeed, malocclusion can interfere with normal swallowing and with nocturnal breathing, which can lead to a worsened sleep quality. ${ }^{3}$ Cavities (due to abnormal chewing and residual food in the mouth) may become painful although the child is not always able to localize the pain, therefore becoming causes of potentially severe infections. We suggest the first dental examination at age 12 months, followed by regular yearly controls.

Early evaluation by an ophthalmologist is also needed: it is important to start an appropriate follow up with the child collaboration, since cataract, optic atrophy, severe myopia and retinopathy are often present but often underdiagnosed and they can cause progressive reduction of visual function and consequent learning difficulties. ${ }^{20,21}$ A good visual function allows not only the use of facilitated communication techniques but also to watch simple TV shows, to leaf through children books, to play videogames, just to mention some of our children interests.

It is important to make a differential diagnosis between problems related to ocular anomalies and impairments caused by general CNS dysfunction, as of course they will be treated differently.

Neuroradiologic evaluation during the diagnostic workup certainly has scientific relevance, but it requires sedation: for instance, MRI that does not use radiation, lasts about twenty minutes, is very noisy and the patients must stay still.

Parents frequently report events of vomiting or crying after meals, which are suggestive of gastro-esophageal reflux. Its formal diagnosis would require tests usually not performed in patients with cognitive deficit. It is likely that postural problems, type of chewing and swallowing impairment might cause frequently some symptoms of dysphagia. Pharmacological treatment is not always necessary and anti-gas medication (such simethicone or activated charcoal) and rehabilitation exercises to remove excess gas can help.

ENT consultation is precious and mandatory during $\mathrm{CdC}$ follow up for audiological and phoniatric evaluation and for swallowing problems management. 22,23 An orthopedic evaluation is recommended in case of flat feet or vertebral scoliosis and it is mandatory in the rapid growth period (prepuberty).

Vertebral scoliosis is idiopathic and the incidence in Cri du chat syndrome is frequent. ${ }^{24}$ The general pediatrician according to clinical suspicion will plan the orthopedic evaluation. Treatment for scoliosis, when clinically requested, should be scheduled as early as possible in $\mathrm{CdC}$ patients, similarly to the procedures in the general population.

Polysomnography (multi-channel recording during normal sleep) can be prescribed in case of sleep apnea, both in high-risk SIDS age and in older ages as screening test, due to the importance of respiratory and neurological problems during the sleep; these tests are usually well tolerated, and allow performing a useful sleep EEG; the experience in $\mathrm{CdC}$ patients is very limited. 25

\section{Adolescence and adulthood}

The most important concern for parents, as reported during meetings of families, is the progressive loss of acquired skills: day care centers seems to be insufficient to maintain the gained autonomy and patients generally seem to move backward. These problems are often generated because of a true decrease in rehabilitation programs. The number, type and frequency of supportive activities in fact decreases with time: in our experience, at the end of adolescence training programs often ends because similar programs for adults are much less available.

In addition, number and type of acquired skills are limited and, for the parents, the hope of further positive development progressively vanishes. Often the problem of losing acquired skills develops simultaneously with parental aging and with the progressive reduction of their emotional and physical "strength". This observation must be an incentive to develop new rehabilitation programs targeted for patients in their twenties. We have many anecdotal reports from families stating that $\mathrm{CdC}$ patients may gain new skills even when it seems to be no longer possible. For this reason, rehabilitation programs should be carried on lifelong.

It is also important to perform periodic general check-up: for instance, a visual impairment can lead to annoyance in using computer or watching TV, but in this case, just a specific ophthalmology evaluation and the use of lenses could restore the interest in some daily activities and help in keeping acquired skills. Similarly, it is quite difficult to keep the attention during the whole day if sleeping quality is poor.

For these reasons, it is important to plan regular control of general health conditions (every two years) across the whole lifecycle (Table 1). We included in Table 2 a proposal to scheduled clinical controls.

No formal evaluations of mortality rates are available, but it is reasonable to assume that after the first year of life, mortality rates

Table 1. Clinical features in Cri du Chat patients at various age.

\begin{tabular}{lccc} 
Clinical features (\%) & At diagnosis & $>10$ years & $>15$ years \\
Typical cry/acute voice & 95.9 & 71.7 & 66.7 \\
Round face & 83.5 & 4.8 & 2.1 \\
\hline Prominent metopic bossing & 70.7 & 28.6 & 29.3 \\
Large nose bridge & 87.2 & 63.2 & 65.1 \\
\hline Downward slanting palpebrals fissures & 56.9 & 26.2 & 29.8 \\
Hypertelorism & 81.4 & 57.6 & 63.0 \\
\hline Epicanthal folds & 90.2 & 60.3 & 56.2 \\
Strabismus divergent/convergent & 47.5 & 44.3 & 44.7 \\
\hline Down turned corners of the mouth & 81.0 & 58.2 & 64.3 \\
Short philtrum & 60.5 & 85.7 & 87.8 \\
\hline Microretrognathia & 96.7 & 73.3 & 71.7 \\
Low-set ears & 69.8 & 31.7 & 32.6 \\
\hline Short neck & 56.2 & 21.6 & 25.6 \\
High arched palate & 83.8 & 58.8 & 57.5 \\
\hline Transverse flexion creases & 92.0 & 90.2 & 95.0 \\
Hypoplasia thenar eminence & 73.7 & 73.2 & 74.3 \\
\hline Small pelvis & 73.8 & 54.5 & 54.2 \\
Diastasis recti & 76.8 & 71.4 & 74.1 \\
\hline Hypotonia & 72.2 & 2.0 & 2.5 \\
\hline
\end{tabular}

Modified from Cerruti Mainardi (2006). ${ }^{2}$ 
Table 2. Medical investigation schedule proposed for Cri du Chat patients at different ages.

\begin{tabular}{|c|c|c|c|c|c|c|c|c|c|c|c|c|c|c|c|c|c|c|c|c|}
\hline \multirow[t]{2}{*}{ Medical investigation } & \multirow[t]{2}{*}{ Birth } & \multicolumn{5}{|c|}{ Months } & \multicolumn{13}{|c|}{ Years } & \multirow{2}{*}{$\begin{array}{c}\text { Follow } \\
\text {-up }\end{array}$} \\
\hline & & 1 & 3 & 6 & 9 & 12 & 2 & 3 & 4 & 5 & 6 & 7 & 8 & 9 & 10 & 11 & 12 & 15 & 18 & \\
\hline Karyotype, other genetic tests, genetic counseling & $*$ & & & & & & & & & & & & & & & & & & & \\
\hline Neonatal screening & * & & & & & & & & & & & & & & & & & & & \\
\hline Cardiac evaluation & $*$ & & & * & & & & & & & & & & & & & & & & \\
\hline Pediatric examination & $*$ & $*$ & * & $*$ & * & * & $*$ & * & * & * & * & $*$ & $*$ & * & * & $*$ & $*$ & $*$ & * & \\
\hline Pediatric neuropsychiatric assessment & $*$ & $*$ & $*$ & $*$ & $*$ & $*$ & $*$ & $*$ & $*$ & $*$ & * & $*$ & $*$ & $*$ & $*$ & $*$ & $*$ & $*$ & $*$ & $*$ \\
\hline Ophthalmological examination & $*$ & & & $*$ & & $*$ & $*$ & $*$ & $*$ & & & $*$ & & & * & & & $*$ & $*$ & * \\
\hline Orthopedic evaluation & & & & & & $*$ & & & $*$ & & & & & * & & & & & & \\
\hline ENT assessment & OAEs & $\mathrm{ABR}$ & & & & & $*$ & $*$ & * & $*$ & * & $*$ & $*$ & * & $*$ & $*$ & $*$ & $*$ & * & \\
\hline Dental examination & & & & & & $*$ & $*$ & & & & $*$ & $*$ & $*$ & * & $*$ & $*$ & & $*$ & $*$ & * \\
\hline Vaccination $^{\circ}$ & & & & & & & & & & & & & & & & & & & & \\
\hline Sleep exam & & & & & & & & & * & & & & & & & & $*$ & & & \\
\hline Anesthesia evaluation & & & & & & * & & & & & & & & & & & & & & \\
\hline Renal and hip ultrasound & & & $*$ & & & & & & & & & & & & & & & & & \\
\hline
\end{tabular}

are not largely increased with respect to general population. . $^{3,4}$

At any age, a difficult topic to consider is "abuse". There are many different kinds of abuse: sexual, psychological, physical but we also include neglect and excessive care. Disabled children put parents and caregivers under strain; therefore, even in an optimal care setting, they could be unintentionally victims of psychological abuse from stressed educators, and the disabled patient is very often unable to report suffering situations. Hence the necessity to remain extremely vigilant in these situations in order to seek help before care burden becomes too heavy (for parents, but also for other caregivers) and to prepare educators to find risk signals in children daily behavior. ${ }^{26,27}$

\section{Final comment}

The literature for follow-up and care in $\mathrm{CdC}$ patients at various ages is limited and no updated guidelines for management of $\mathrm{CdC}$ patients at different ages are available. Conversely, there is an increasing amount of data concerning new tests for evaluating severity and types of physical and developmental handicaps or new rehabilitation procedures.

We intend this report, derived from the experience of a multidisciplinary group working in the setting of the Italian health care, as a proposal to stimulate discussion with the aim to deliver shared recommendations specifically devoted to $\mathrm{CdC}$ patients.

\section{References}

1. Simmons AD, Goodard SA, Gallardo TD, et al. Five novel genes from the cridu-chat critical region isolated by direct selection. Hum Mol Genet 1995;4:295302.

2. Cerruti Mainardi P. Cri du Chat syndrome. Orphanet J Rare Dis 2006; 1:33.

3. Cerruti Mainardi P, Pastore G, Castronovo $\mathrm{C}$, et al. The natural history of Cri du Chat Syndrome. A report from the Italian Register. Eur J Med Genet 2006;49:363-83.

4. Guala A, Spunton M, Kalantari S, et al. Neoplasia in Cri du Chat Syndrome from Italian and German Databases. Case Rep Genet 2017;2017:5181624.

5. Cornish K, Bramble D. Cri du chat syndrome: genotype-phenotype correlations and recommendations for clinical management. Dev Med Child Neurol 2002;44:494-7.

6. Cerruti Mainardi P, Pastore G, Guala A. Sindrome del cri du chat. In: Balestrazzi P. (ed). Linee guida assistenziali nel bambino con sindrome malformativa. Milano: CSH; 1994. pp. 75-90.

7. Lariccia F, Pinnelli A, Prati S, et al. L'appropriatezza del taglio cesareo nelle regioni italiane: analisi con la classificazione di Robson. Riv Ital Econ Demogr Stat 2014;68:175-82.

8. Hills C, Moller JH, Finkelstein M, et al. Cri du chat syndrome and congenital heart disease: a review of previously reported cases and presentation of an additional 21 cases from the Pediatric Cardiac Care Consortium. Pediatrics 2006;117:e924-7.
9. Thangaratinam S, Brown K, Zamora J, et al. Pulse oximetry screening for critical congenital heart defects in asymptomatic newborn babies: a systematic review and meta-analysis. Lancet 2012;379:2459-64.

10. Akinpelu OV, Peleva E, Funnel WR, Daniel SJ. Otoacustic emissions in newborn hearing screening: a systematic review of the effect of different protocols on test outcomes. Int $\mathrm{J}$ Pediatr Otorhinolaryngol 2014;78:711-7.

11. Sun M, Ma A, Li F, et al. Sensitivity and specificity of red reflex test in newborn eye screening. J Pediatr 2016;179:1926.

12. Gazzetta Ufficiale della Repubblica Italiana, GU n ${ }^{\circ} 267$ del 15 -11-2016.

13. Kjaer I, Niebuhr E. Studies of cranial base in 23 patients with cri-du-chat syndrome suggest a cranial developmental field involved in the condition. Am J Med Genet 1999;82:614.

14. Ninchoji T, Takanashi J. Pontine hypoplasia in 5p-syndrome: a key MRI finding for a diagnosis. Brain Dev 2010;32:571-3.

15. Irwin LG, Arjumand Siddiqi RN, Hertzman C. Early Child Development: A powerful equalizer. Final report for the World Health Organization's Commission on the social determinants of health, 2007. Available from: http://apps.who.int/iris/bitstream/10665/ 69729/1/a91213.pdf?ua=1

16. Nardi S. The cri du Chat syndrome; Technical aspects and educational guidelines. 2014. Available from: http://www.criduchat.it/ABC_Criduchat English.htm

17. Cornish K, Oliver C, Standen P, et al. 
Cri-du-Chat syndrome, handbook for Parents and Professionals. 2003. Available from: http://criduchat.org.uk/downloads/handb ook.pdf

18. Guala A, Spunton M, Cerruti Mainardi $\mathrm{P}$, et al. Anesthesia in Cri du Chat syndrome: Information on 51 Italian patients. Am J Med Genet A 2015;167A:1168-70.

19. A.B.C. Associazione Bambini Cri du chat Onlus. Curve di crescita. Available from:

http:/www.criduchat.it/documents/curv e_crescita_scdc.pdf

20. Rodriguez Caballero A, Torres Lagares
D, Yanez Vico RM, et al. Assessment of orofacial characteristics and oral pathology associated with cri du chat syndrome. Oral Dis 2012;18:191-7.

21. Hope WH, Cordovez JA, Capasso JE, et al. Peters anomaly in cri-du-chat syndrome. J AAPOS. 2015;19:277-9.

22. Kristoffersen KE. Speech and language development in cri du chat syndrome: a critical review. Clin Linguistic Phon 2008;22:443-57.

23. Virbalas JM, Palma G, Tan M. Obstacles to communication in children with cri du chat syndrome. J Voice 2002;26:821.

24. Takebayashi T, Obata H, Minaki Y, et al. Scoliosis in cat cry syndrome. J Orthop Sci 2006;11:259-63.
25. Maas AP, Didden R, Korzilius H, et al. Sleep in individuals with cri du chat syndrome: a comparative study. J Intellect Disabil Res 2009;53:704-15.

26. Hughes K, Bellis MA, Jones L, et al. Prevalence and risk of violence against adults with disabilities: a systematic review and meta-analysis of observational studies. Lancet 2012;379:1621-9.

27. Jones K, Bellis MA, Wood S, et al. Prevalence and risk of violence against children with disabilities: a systematic review and meta-analysis of observational studies. Lancet 2012;380:899-907. 